\title{
UK landscape ecology: trends and perspectives from the first 25 years of ialeUK
}

\author{
Christopher Young (D) Chloe Bellamy $(\mathbb{D} \cdot$ Vanessa Burton $(\mathbb{D}) \cdot$ Geoff Griffiths $(\mathbb{D} \cdot$ \\ Marc J. Metzger $(\mathbb{D} \cdot$ Jessica Neumann $(\mathbb{D} \cdot$ Jonathan Porter $(\mathbb{D} \cdot$ James D. A. Millington $(\mathbb{D}$
}

Received: 16 September 2019/Accepted: 25 November 2019/Published online: 3 December 2019

(C) The Author(s) 2019

\begin{abstract}
Context The 25th anniversary of the founding of the UK chapter of the International Association for Landscape Ecology (ialeUK) was marked in 2017.

Objectives To assess trends in UK landscape ecology research over ialeUK's first 25 years, to compare these trends to changes elsewhere in the world, and to consider how ialeUK can continue to support landscape ecology research and practice.

Methods A database of conference abstracts was compiled and examined in combination with a questionnaire that surveyed existing and former active members of ialeUK.
\end{abstract}

C. Young $(\bowtie)$

School of Sciences, University of Wolverhampton, Wulfruna Street, Wolverhampton WV1 1LY, UK

e-mail: C.H.Young@wlv.ac.uk

C. Bellamy · V. Burton

Forest Research, Northern Research Station, Roslin, Edinburgh EH25 9SY, UK

e-mail: chloe.bellamy@ForestResearch.gov.uk

V. Burton

e-mail: Vanessa.Burton@ed.ac.uk

V. Burton · M. J. Metzger

School of GeoSciences, The University of Edinburgh,

Drummond Street, Edinburgh EH8 9XP, UK

e-mail: marc.metzger@ed.ac.uk
Results Across 1992-2017 we observe noticeable trends including the declining roles of statutory bodies, the development of the ecosystem services concept, and a decrease in use of empirical methods. Analysis of questionnaire results highlighted four key areas: Developing new researchers; Facilitating conferences for networking, learning and discussion; Linking policy with practice; and Driving the continued growth of landscape ecology as a discipline. Challenges were also noted, especially regarding the adoption of a wider understanding of landscape ecological principles in management.

Conclusions Increases in qualitative research, decreases in studies explicitly examining

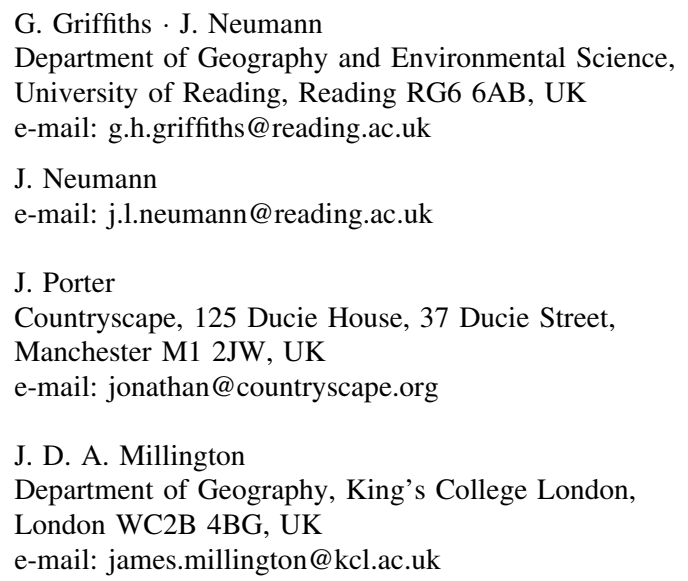


connectivity/fragmentation and an absence of landscape genetics studies in the UK are seemingly distinct from US landscape ecology and elsewhere around the world, based on published accounts. ialeUK has had success in increasing the role of landscape ecology in policy and practice, but needs to continue to aim for improved collaboration with other landscape-related professional bodies and contributions to wider sustainability agendas.

Keywords ialeUK conferences - Policy and practice $\cdot$ New researchers - Landscape ecological trends · Continuity and diversity

\section{Introduction}

With 2017 marking the 25th anniversary of the founding of the UK chapter of the International Association for Landscape Ecology (ialeUK), current members of its organising committee set out to examine the content of past ialeUK conferences and, with input from past ialeUK contributors, reflect on what observed patterns might mean for shaping future landscape research. Three questions guided our analysis with the aim of better understanding the contribution of ialeUK and its position within the broader field of landscape ecology:

- What trends are there in UK landscape ecological research as evidenced by the ialeUK conference proceedings?

- How do any trends identified in UK landscape ecology compare to the discipline elsewhere in the world?

- How can ialeUK best support landscape ecology research and practice into the future?

Although the International Association for Landscape Ecology (IALE) had existed for a number of years, in the early 1990s UK members felt that a UK chapter was necessary to reflect both the chapterfocused organisational structure that lay at the heart of IALE and the significant number of UK professionals contributing to the development of the discipline. The meeting notes from the inaugural ialeUK meeting in November 1991 record that one of the agreed key aims of the chapter should be to, "actively organise workshops/training events and conferences for the further interaction between scientists, managers and planners in the field of landscape ecology". Subsequently, the ialeUK chapter was formally established and held its first constituted meeting in January 1992.

Since formation, ialeUK has held a conference each year (other than in 2003 and 2007 due to limits on resources and 2013 when ialeUK hosted the European Congress; see Table 1). Conferences are organised by the committee, who collectively select an overall theme and subtopics with which to focus sessions on; these single-group sessions are run in series (rather than in parallel) over 2-3 days. Themes are selected to reflect trends emerging in research, policy agendas and land management practices relevant to landscape ecology in the UK at that time. As such, it is more of a response to, rather than a driver of, landscape ecology developments (although the ideas and collaborations generated by conference participation are likely to have some influence on future directions in the discipline). As these meetings form such a core part of the ialeUK operation, proceedings containing abstracts of the oral and poster presentations made at each of the 22 annual conferences since 1992 are the most tangible indication of past trends in UK landscape ecology. Here, we present an overview of the content of the conference abstracts, which have been compiled into a database.

In addition, through an online questionnaire, we solicited views on the following questions:

(1) In its 25 years what contribution has ialeUK made to Landscape Ecology as a discipline?

(2) What have been the particular successes of ialeUK?

(3) What challenges remain for landscape ecology in the UK?

(4) What role do you see for ialeUK in the next 25 years?

The questions were designed to elucidate more personal perspectives of the development of landscape ecology in the UK through the prism of ialeUK. The questions were open-ended to encourage individuals to express opinion and to capture diverse responses without bias (Reja et al. 2003). By reflecting the history of ialeUK through conference abstracts and the knowledge of both long-standing and newer members we offer insights into UK landscape ecology that may be valuable to our members and other chapters. We also hope to open a conversation on the regional 
Table 1 List of ialeUK conferences ( $-=$ no UK conference)

\begin{tabular}{|c|c|c|c|}
\hline Year & Conference Theme & Location & $\begin{array}{l}\text { No. of } \\
\text { abstracts }\end{array}$ \\
\hline 1992 & Landscape Ecology in Britain & Nottingham & 19 \\
\hline 1993 & The Ecology and Management of Cultural Landscapes & Cheltenham & 12 \\
\hline 1994 & Fragmentation in Agricultural Landscapes & Preston & 30 \\
\hline 1995 & Landscape Ecology: Theory and Application & Reading & 44 \\
\hline 1996 & The Spatial Dynamics of Biodiversity & Stirling & 33 \\
\hline 1997 & Species Dispersal and Land Use Processes & Coleraine & 62 \\
\hline 1998 & Key Concepts in Landscape Ecology & Manchester & 62 \\
\hline 1999 & Heterogeneity in Landscape Ecology: Pattern and Scale & Bristol & 33 \\
\hline 2000 & Quantitative Approaches to Landscape Ecology & Bangor & 24 \\
\hline 2001 & Hedgerows of the World: Their Ecological Functions in Different Landscapes & Birmingham & 58 \\
\hline 2002 & Avian Landscape Ecology: Pure and Applied Issues in the Large-scale Ecology of Birds & Norwich & 71 \\
\hline 2003 & No conference & & - \\
\hline 2004 & Landscape Ecology of Trees and Forests & Cirencester & 66 \\
\hline 2005 & Planning, People and Practice: The Landscape Ecology of Sustainable Landscapes & Northampton & 29 \\
\hline 2006 & Water and the Landscape: The Landscape Ecology of Freshwater Ecosystems & Oxford & 58 \\
\hline 2007 & No conference & & - \\
\hline 2008 & Landscape Ecology and Conservation & Cambridge & 24 \\
\hline 2009 & Ecological Networks: Science and Practice & Edinburgh & 33 \\
\hline 2010 & Future Landscape Ecology & Brighton & 33 \\
\hline 2011 & Landscape Ecology and Ecosystem Services & Wolverhampton & 46 \\
\hline 2012 & Landscape Ecology: Linking Environment and Society & Edinburgh & 36 \\
\hline 2013 & $\begin{array}{l}\text { Changing European Landscapes: Landscape Ecology, Local to Global (IALE-Europe } \\
\text { conference hosted by ialeUK) }\end{array}$ & Manchester & - \\
\hline 2014 & Urban Landscape Ecology: Science, Policy and Practice & London & 40 \\
\hline 2015 & Seascape Ecology: Connecting Land, Sea and Society & Edinburgh & 40 \\
\hline 2016 & Landscape Characterisation: Methods \& Applications in Landscape Ecology & Reading & 27 \\
\hline 2017 & 25 Years of Landscape Ecology & Manchester & 46 \\
\hline
\end{tabular}

variation of our discipline and how we can continue to thrive globally under future political, environmental and economic climates.

\section{Trends across 25 years of ialeUK conferences}

Since the 2012 conference, proceedings have been produced in digital format. These are available online at https://iale.uk/conferences, with prior proceedings published in paper format and papers from the 2014 conference published in an edited book (Francis et al. 2016). We compiled a database by reviewing a total of 914 abstracts of oral and poster presentations published in available conference proceedings since 1992. We characterised abstracts using pre-defined classes within eight categories (Table 2) with the categorisation allowing an abstract to be labelled as more than one class/category. Where authorship was divided among several authors the lead author's organisation was used for classification purposes. Similar approaches have been used to examine trends in publications across the discipline in Landscape Ecology journal (Andersen 2008; Wu 2017) and specifically at USIALE conferences (McIntyre et al. 2013). We acknowledge that the outcome of our analysis will reflect the categories used, but by selecting categories based on our prior knowledge of ialeUK conferences and used previously by other reviews we are able to both ensure coverage of content within the UK and enable comparison beyond. 
Table 2 Categories and classes used to characterise conference abstracts

\begin{tabular}{|c|c|}
\hline Category & Classes \\
\hline $\begin{array}{l}\text { Author } \\
\text { Affiliation }\end{array}$ & Academic, Government, NGO (Non-Government Organisation), Business, Private \\
\hline $\begin{array}{l}\text { Landscape } \\
\text { Type }\end{array}$ & Upland Rural, Lowland Rural, Urban, Riverscape, Seascape, Undefined, Other \\
\hline Organism & Mammals, Humans, Birds, Reptiles, Inverts, Plants, Amphibians, Fish, Generic Habitat, Woodland/Forests \\
\hline Methods & Empirical, Theoretical, Qualitative, Quantitative, Geographical Information Systems (GIS), Remote Sensing (RS) \\
\hline Spatial Extent & $\begin{array}{l}\text { Micro (less than } 1 \mathrm{ha}) \text {, Mini }\left(1 \mathrm{ha}-10 \mathrm{~km}^{2}\right) \text {, Local }\left(10-100 \mathrm{~km}^{2}\right) \text {, Regional }\left(1000-10,000 \mathrm{~km}^{2}\right) \text {, National } \\
\text { Continental, Global, Undefined }\end{array}$ \\
\hline $\begin{array}{l}\text { Temporal } \\
\text { Extent }\end{array}$ & Hours, Days, Weeks, Months, Years, Decades, Centuries, Longer, Undefined \\
\hline Concepts & $\begin{array}{l}\text { Pattern-Process-Scale relationships of landscapes (Pat-Proc-Scale), Landscape Connectivity and Fragmentation, } \\
\text { Scale and Scaling, Spatial Analysis and Landscape Modelling, Land Use and Land Cover Change (LUCC), } \\
\text { Landscape History and Legacy Effects, Landscape and Climate Change Interactions, Ecosystem Services in } \\
\text { Changing Landscapes (Eco services), Landscape Sustainability, Accuracy Assessment and Uncertainty Analysis } \\
\text { (Acc and uncertainty) }\end{array}$ \\
\hline Other Concepts & $\begin{array}{l}\text { Green Infrastructure, Planning and Architecture, Management and Conservation (Mgmnt \& Conserv), Cultural } \\
\text { Landscapes (Cultural Lsps), Socio-economic Dimensions, Biodiversity, Landscape Assessment (Lsp } \\
\text { Assessment), Catchment Based Approach, Invasives, Pests \& Diseases }\end{array}$ \\
\hline
\end{tabular}

To understand how the composition of contributors to ialeUK conferences has changed we recorded Author Affiliations and considered possible variations in landscapes by identifying the focal Landscape Type investigated in each study. We included a Methods category to explore trends in landscape ecology approaches and, to consider how the spatio-temporal scope of studies may have varied, we included Spatial Extent and Temporal Extent categories. Focal topics of abstracts were characterised using Organism, Concepts and Other Concepts categories. Multiple classes in each category could be assigned to any abstract, depending what was deemed appropriate by the reviewer. Below we focus on trends in these categories through time but also highlight what seem to be the clearest patterns in the data, with brief commentary on what the primary drivers might be. A more complete analysis of the database is freely available (Millington 2019).

\section{Overall contributions}

The total number of conference abstracts initially increased through time, from 19 in the first conference to a peak of 71 a decade later in 2002 (Table 1).
Abstracts in each conference then decreased until the later 2000s, becoming relatively stable at around 40 abstracts each year. This contrasts with US-IALE which increased attendance during the 1990s to a point which has remained relatively stable since (McIntyre et al. 2013). While the exact reasons for the recent decline in participation in ialeUK conferences are difficult to confirm they are likely related to an increase in competing conferences (e.g. those organised by IALE-Europe), decline in meeting attendance from regulatory and statutory bodies for the environment that were often key contributors in the earlier years (e.g. Natural England), and popularity of conference themes in any given year. This recent average of 40 abstracts per conference reflects the preferred format of single-group sessions of $15 \mathrm{~min}$ long oral presentations over two days, often with an additional half-day of fieldtrips. The composition of contributions has not showed consistent trends over time: some years are notably distinct in one or more aspects of their composition (Fig. 1), such as Landscape Type in 2005/06 and 2014/15 (Fig. 1b), Organism in 2002 (Fig. 1c), Method in 1992 and 1997 (Fig. 1d), and Temporal Extent in 2005, 2010 and 2012. These differences are associated with the 
conference theme of a given year. The single-group session format adopted likely makes them more prone to this variation in composition compared to larger conferences with a multi-session format (e.g. USIALE).

\section{Author affiliation}

The increase in total conference contributions through the 1990s was driven by a growing number of academic contributions, leading to a relative decrease in the proportion of contributions from governmental agencies (Fig. 1a). However, since the mid-2000s the absolute number of contributions from Government authors has declined (mean of 17 pre-2005, mean of 6 post-2004), while contributions from NGOs has increased slightly (mean of 4 pre-2005, mean of 6 post-2004). This seems to mirror the changing priorities of the UK government in moving away from strong centrally-funded statutory bodies to a more devolved model and the commensurate changes in job roles, organisational economics and the limited support for applied work beyond basic regulatory implementation (e.g. JNCC 2010). Across all years, Academic contributions dominate $(55 \%)$ followed by Government (27\%). Although Business contributors are present at many conferences, they represent only a small proportion (4\%) and their contributions are almost exclusively non-empirical, possibly reflecting the costs of such studies.

\section{Landscape type}

Although there are no stark trends through time (Fig. 1a), there is a clear emphasis of some landscape types in individual years given the particular theme of the conference that year (i.e. Riverscapes in 2006, Urban in 2014 and Seascapes in 2015). Urban landscape types do not appear in the abstracts before 1998, which may reflect a change in UK politics in 1997 (Wilson and Hughes 2011) with new urban greenspace policy and targets developed by the newly elected government, such as England's Accessible Natural Greenspace Standard (ANGSt; Handley et al. 2003), in line with a growing recognition of the benefits that parks, gardens and other urban greenspace provide (Wilson and Hughes 2011). While Lowland Rural landscape types generally provided the majority of studies before 2005, they have declined in recent years with a rise in the relative interest in other landscape types. However, across all years, Lowland Rural landscape types dominate conference contributions (41\%), which is possibly not surprising given the effects of fragmentation, infrastructure, agricultural intensification and urban sprawl in these landscapes, but also given their relative prominence across the UK (e.g. Natural England 2014). The next largest group of studies does not define any specific landscape type, largely because these abstracts indicate a focus on multiple landscape types (rather than no landscape type being specified). Qualitative methods were applied to seascapes more than for any other landscape type; Green Infrastructure is studied mostly in Urban landscapes and Catchment-Based Approaches are seen most often in Riverscapes. By contrast, we were surprised to find that there are few representatives of Cultural Landscape studies (that is studies focussing on people's behaviours, preferences or attitudes in association with the landscape) in Urban landscapes; this may reflect the perception of ialeUK conferences as being more science-focused, as opposed to culturally-oriented conferences hosted by other UK landscape organisations (e.g. the Landscape Institute).

\section{Organism}

Focal organisms of study have varied considerably through time (Fig. 1c), and, as for landscape type, localised peaks are associated with particular conferences (e.g. Birds in 2002 in which the conference theme was Avian Landscape Ecology). Even taking these peaks into account it is clear that some organism groups are not as well studied, including amphibians (2\% of all abstracts), fish (2\%) and reptiles (1\%). Studies of plants were conducted over longer time periods (decades/centuries) while invertebrate studies were conducted over shorter periods (annual and monthly). There are very few studies of any organism over time periods shorter than Months $(\sim 0.005 \%$ of all abstracts). In terms of Author Affiliation, Bird studies tend to be dominated by NGOs reflecting the strength of such organisations focusing on bird conservation within the UK. Perhaps surprisingly, bearing in mind the obvious application of remotely sensed data for habitat monitoring, Plant studies infrequently used Remote Sensing Methods (0.5\%). Unsurprisingly, invertebrates are dominated by applied 'mini' spatial extent studies (1 ha-10 km²), 
(a) Author Affilitation

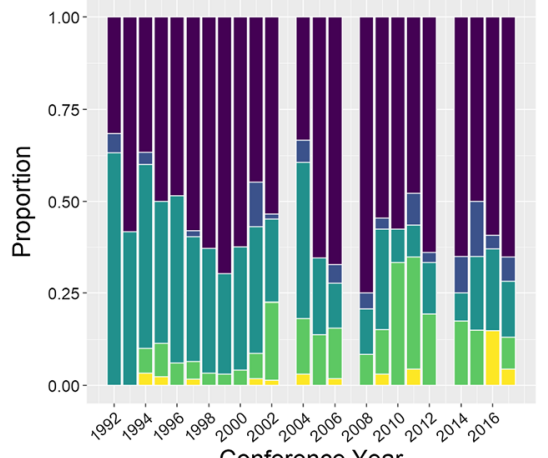

(c) Organism

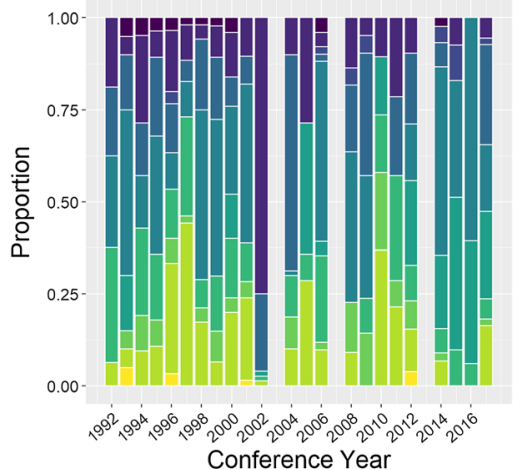

(e) Spatial Extent

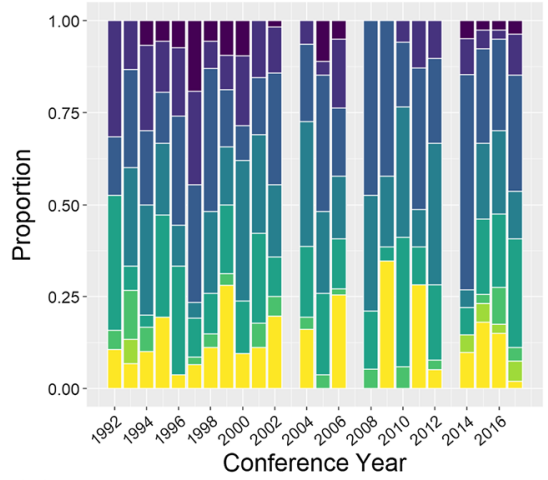

(g) Concepts

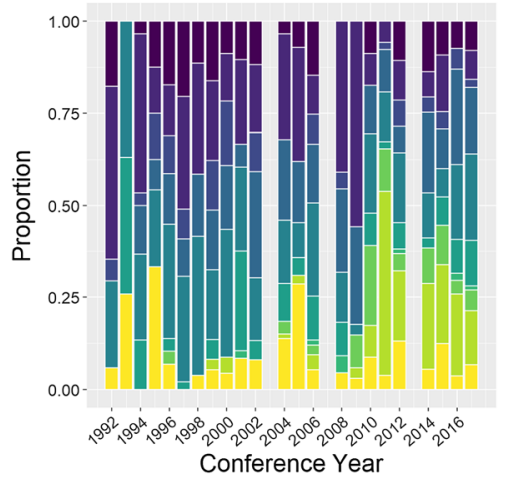

(b) Landscape Type

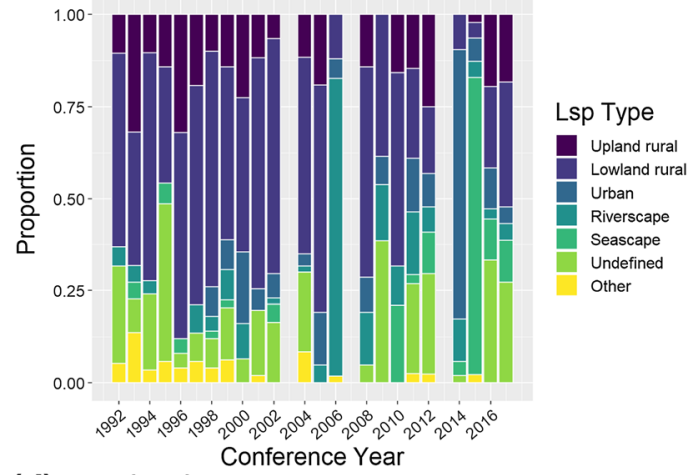

(d) Method
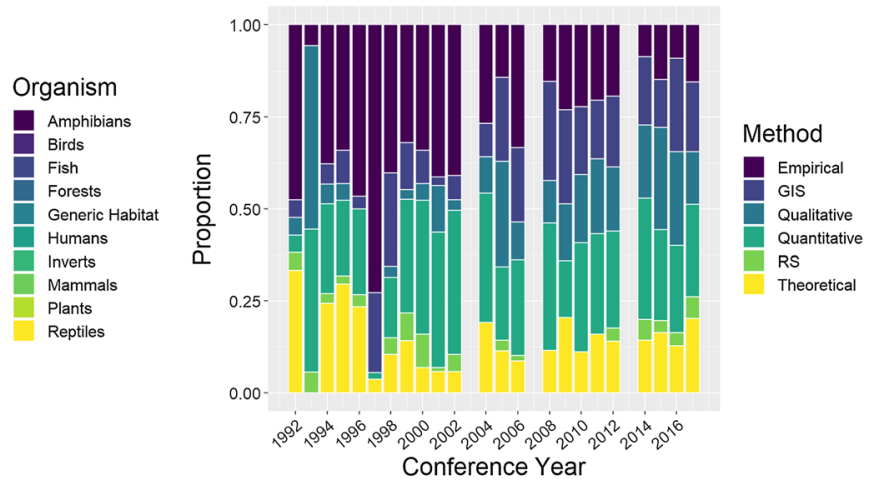

(f) Temporal Extent

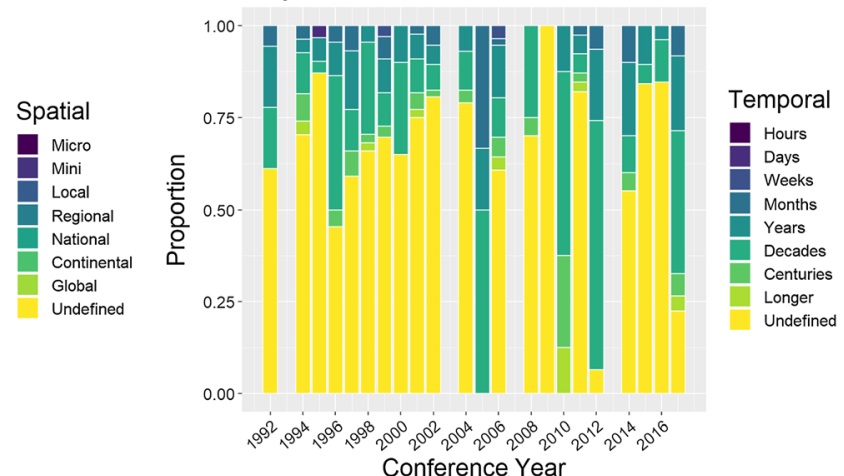

(h) Other Concepts
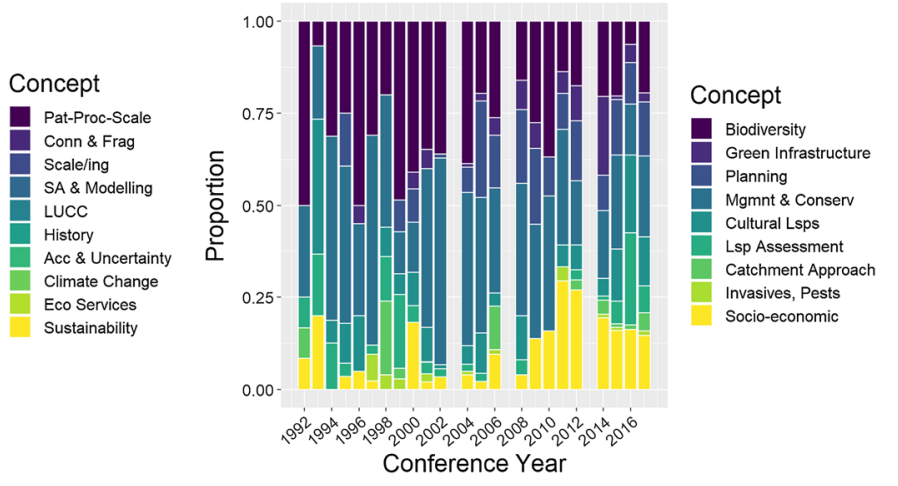

Conference Year 
4Fig. 1 Proportions of conference abstracts falling into each pre-defined class over the past 25 years (1992-2017). For meaning of abbreviations - see Table 2

providing exemplars of sites and species within a spatially constrained landscape context at scales appropriate for their life history strategies.

\section{Method}

Most of the studies presented were Empirical and Quantitative (58\% of all abstracts). In early conferences, studies were often dominated by Empirical methods (in the sense of collecting and analysing primary data; mean of $43 \%$ 1992-2002), but since 2007 they are a minor contributor (mean of $17 \%$ 2008-2017; Fig. 1d). This decrease may be related to the costs of empirical study, potentially to the decrease in Government contributors research in UK landscape ecology (as noted above), and increases in use of modelling (quantitative methods have remain consistently used) and secondary or monitoring data used with GIS (see below). In later years the distribution of methods has evened-out and there has been a noticeable increase in Qualitative methods, many of which focused on Socio-Economic dimensions and Cultural Landscapes, a trend that has not been noted in previous reviews (e.g. McIntyre et al. 2013, Wu 2017). This increase may be associated with the rise of the ecosystem services framework, and efforts to improve methodologies which capture cultural and non-use values (Chan et al. 2012, Hernández-Morcillo et al. 2017). Across years there is surprisingly little in the way of Remote Sensing (RS) being used (3\% of all abstracts) while use of Geographic Information Systems (GIS) increased from low levels of application pre-2005 to now remaining steady at around $20 \%$ of abstracts each year. The seemingly continued low use of RS may be because authors have classified it under the umbrella term of GIS, with methods frequently employed together and managed by software packages that integrate both techniques. The increase in use of GIS is consistent with greater application across the discipline, although relative to Landscape Ecology publications examined by Andersen (2008) there was seemingly a lag in the uptake in UK landscape ecology behind that in other regions (at least in terms of work presented at ialeUK conferences). Particularly noteworthy is that despite the increasing presence of Ecosystem Services at conferences, there are relatively few examples of Empirical studies of the concept.

\section{Spatial extent}

Across all abstracts in all years, studies at Intermediate spatial extents have dominated. That is, Local $\left(10-100 \mathrm{~km}^{2}\right)$ studies $(28 \%$ of all abstracts, $32 \%$ when undefined extents are excluded) and Regional (1000-10,000 $\mathrm{km}^{2}$ ) studies (20\% and 24\%), with fewer at larger $\left(>10,000 \mathrm{~km}^{2}\right)$ and fewest at smaller $\left(<10 \mathrm{~km}^{2}\right)$ spatial extents. This dominance of the Intermediate spatial extent reflects the landscape scale of the UK, with its unusual diversity of landscapes over such scales. Through time there are no clear trends or changes in the spatial extent of studies (as found by Andersen 2008 for studies across the discipline 1987-2005), although Local studies peak in 2014 (59\%) which was the year of the Urbanthemed conference (Fig. 1e). The large proportion of Local studies in that year then makes sense given the vast majority of urban areas in the UK are smaller than our definition of Local (i.e. $\leq 100 \mathrm{~km}^{2}$; ONS 2017). The smallest extents (micro and mini) have the largest proportions of Biodiversity studies and these are often closely linked to the behavioural scales of the organism under study. However, such smaller extents are not seen in those studies examining SocioEconomic aspects of landscapes. All extents demonstrate consistent proportions of Management and Conservation studies reflecting the importance of that broad topic area as a key driver in the development and application of UK landscape ecology.

\section{Temporal duration}

The majority of abstracts $(65 \%)$ did not report the duration of their study. Given the spatial emphasis of most landscape ecology studies this is unsurprising, but in future more detail on the temporal dimension of studies needs to be encouraged. Of those studies that did report a duration, in most years the majority of studies operated over time periods of Years or longer (Fig. 1f). It was also notable that studies of Urban landscapes were over shorter durations (Months and Weeks) when compared with other landscape types. 


\section{Concepts}

Across all abstracts reviewed, the most frequent concepts addressed were Land Use/Cover Change (20\%), Connectivity/Fragmentation (19\%) and Spatial Analysis and Modelling (17\%). However, while absent in earlier conferences, Climate Change and Ecosystem Services have become regularly studied in recent years (composing 13\% and $37 \%$ of conference abstracts since 2010, respectively; Fig. 1g), a pattern that has been observed elsewhere (McIntyre et al. 2013; Wu 2017). In contrast, whereas McIntyre et al. (2013) found that connectivity has been consistently represented at US-IALE conferences and despite a rise in connectivity research as reported by some studies (e.g. in urban contexts, Crooks and Sanjayan 2006; LaPoint et al. 2015, and more generally), the proportional representation of Connectivity/Fragmentation studies has decreased over the past 25 years of ialeUK meetings. This may be explained by the increasing popularity of other concepts (see Other "Concepts" section) and also a much wider knowledge and understanding of fragmentation to the point where it has become 'mainstream' in conservation and management, certainly in the case study-type material frequently presented at ialeUK conferences. Studies of Ecosystem Services had the smallest proportion of Empirical studies, the largest proportion of Global extent studies, and fewest Mini and Micro studies.

\section{Other concepts}

Of all the work presented at conferences, studies considering Management and Conservation and Biodiversity compose the majority (56\%), both comprising relatively large proportions of Connectivity and Fragmentation studies. Studies addressing Biodiversity have generally decreased through time as a proportion of conference contributions, with commensurate increases in Socio-Economic and Planning studies since the mid-2000s (Fig. 1h). This perhaps reflects a move towards concepts such as ecosystem services, scenario visualisation (as captured in Qualitative/Cultural Landscapes categories) and seascapes, as opposed to earlier conferences focused on more biodiversity-weighted themes of species dispersal (1997) or birds (2002). Biodiversity and Management and Conservation studies also have greatest proportions of Empirical methods and lowest proportions of
Theoretical approaches. Across the other concepts we considered, Biodiversity studies examined a relatively large proportion of Invertebrates. Despite methods in landscape ecology being strongly relevant, Invasive Pests have been examined very infrequently at ialeUK conferences (considered in only $1 \%$ of abstracts). Throughout the concepts we considered, both Micro and Macro studies are not well represented with (as elsewhere) Decadal timescales dominating.

Just as there are numerous writings on the trajectory of landscape ecology as a discipline (including variation in the rate of change and specific emphases between regions, for example Farina (2000); Antrop (2007); With (2019)), there are numerous ways that we might summarise and characterise UK landscape ecology from our brief analysis of conference abstracts. Antrop (2007) charted writings on landscape ecology as a shift from an initial dominance of descriptive approaches towards spatial modelling and simulation. Our observed decline in studies using empirical methods that collect and analyse primary data may match such a shift away from a descriptive approach, but the use of landscape pattern metrics for description has never been as strong an issue in the UK as it has been elsewhere (e.g. China, Fu and Lu 2006). However, notwithstanding the influence of individual conference themes, studies of urban and cultural landscapes have increased recently at ialeUK meetings and in this the UK shares some of the emphases of landscape ecology in Asia (e.g. Hong et al. 2010). The scale and longevity of human occupation also means that landscape ecology in the UK is characterised more by work within the European tradition of concern about character and the human role in shaping landscapes than a North American perspective of humans as a disturbance factor (sensu Antrop 2007). Similarly, understanding the role of traditional and indigenous knowledge is less prominent in UK landscape ecology than in other regions where industrialisation occurred later (e.g. Asia; Hong et al. 2010) or where European cultures displaced or disrupted others' (e.g. Meurk and Swaffield 2000 in NZ, Waller and Reo 2018 in USA).

Recently, Wu (2017) highlighted several 'hot topics' in the discipline over the last decade; landscape genetics, urban landscape ecology, ecosystem services and landscape sustainability. A key trend we observe at ialeUK meetings is the decrease in studies examining Biodiversity and Connectivity/Fragmentation 
versus increases in Socio-Economic, Climate Change and Ecosystem Services studies. It may be that the apparent decrease in studies of the more 'traditional' issues are because they are now being considered within more contemporary contexts associated with the increasingly transdisciplinary nature of landscape ecological research and the global challenges being faced in the twenty-first Century (Naveh 2007). But not all newer issues in landscape ecology have been represented at ialeUK conferences. For example, although we did not include 'landscape genetics' as a concept in our data collection (and so it cannot be explicitly analysed in our data), the choice of concepts was driven by our a priori knowledge of conference content and anecdotally we know that although this is a fruitful area of landscape research (as also demonstrated by Manel et al. 2003) there has been very limited attention given to the issue at ialeUK conferences. Whilst the reasons are unclear it perhaps reflects the more ecological forums in which colleagues working in landscape genetics are presenting their research in the UK, e.g. the British Ecological Society Annual Conferences. Similarly, the traditions of landscape ecology in Europe have been more influenced by land-use planning and the management of cultural landscapes as compared to the more ecological landscapes focus in North America (With 2019). Yet, despite omission of some topics that are growing elsewhere in the discipline, in general we see our analysis as providing evidence that UK landscape ecology does reflect broader shifts across the discipline, particularly with respect to the importance of climate change, ecosystem services, an understanding how landscapes are connected within a globalised world (e.g. Plieninger et al. 2016) and how we can help meet sustainability challenges under rapid environmental change (Naveh 2007).

\section{The past and future of ialeUK as viewed by members}

The questionnaire was sent out to the full UK membership during the first part of 2017 and individuals who were known to be actively involved with ialeUK over the first 25 years were particularly encouraged to respond. The result was 16 responses from a range of individuals covering policy, practice and academia and also representing engagement with
ialeUK in a range of capacities (from recent conference participants through to past presidents) over the first 25 years of its existence. These respondents comprise about half of people who were specifically invited to respond, as a result we would suggest that while it is a small sample is represents a fair crosssection through the individuals who have had substantive roles in ialeUK or have been long-term members/regular conference attenders throughout the period. Some of the authors were also included in the responses as several had been involved with ialeUK for significant periods of its existence and it was felt that it was important to include their feedback on their experience.

Examination of the questionnaire responses suggest four major interlinking contributions specifically emerging around the work of ialeUK over the past 25 years:

(1) Developing new researchers;

(2) Facilitating conferences for networking, learning and discussion;

(3) Linking policy with practice; and

(4) Driving the continued growth of landscape ecology as a discipline.

Of these, the most frequently commented-on was the welcoming nature of the organisation particularly towards early career researchers and $\mathrm{PhD}$ students reflecting the integral and equal role of postgraduate students on the committee and the aim of ialeUK to welcome junior researchers. Typical responses include, "...student events and workshops have brought young researchers into the discipline" and "For students, I like the fact that the annual student event includes a training element as well as a forum for networking." This links strongly to the second major contribution about the importance of the events and conferences in providing opportunities for knowledge exchange among professional landscape ecologists. Comments such as "friendly conferences", "the conferences and events are always super-friendly" and "high quality annual conferences" reflect the importance of these for ialeUK and the wider landscape ecology community. Conferences were also highlighted for their importance in linking policy and practice; "The conferences have offered a real range of topics and have been a forum for presenting and discussing excellent research and other initiatives in policy and practice." Indeed the sharing of 
information between policy, practice and academia was identified by several respondents as a consistent third theme, e.g. "ialeUK has provided a friendly hub of knowledge exchange and networking for researchers, policy makers, ecological consultants and practitioners". More generally, responses ranging from straightforward statements about the importance of "bringing science, policy and practice together" to more strategic comments about how ialeUK has "...consistently championed the integration of academics, researchers and practitioners", further highlight the role of ialeUK in forging links. Indeed one respondent stated categorically they did not know of "another organisation that achieves this [combination of activities] as well as ialeUK". Finally, the role of ialeUK in both reflecting subject-related ecological changes and driving these as areas was identified as a distinct feature. Most respondents noted this to some degree with comments such as ialeUK has "supported continual development of landscape ecological science", "It has raised the profile of Landscape Ecology" and "ialeUK is recognised as one of the active and leading chapters of IALE" being characteristic.

Despite changes in perspective over the past 25 years, for example with landscape ecology in the UK now being enshrined in policy in the strategic view of 'bigger, better, better connected' nature reserves and wider countryside (Lawton et al. 2010), there still remain challenges for ialeUK to rise to. Responses about ongoing challenges generated an identifiable theme around communicating with non-landscape ecologists; "explaining what landscape ecology is to those outside of the landscape ecology community and how what they do is actually landscape ecology...but they don't realise it!", and perhaps more importantly "to make more people aware that landscape ecology applies to the work they do". Some suggested that this challenge can only be achieved through working with other sectors "getting more businesses on board and using landscape ecology principles" and thus indicating the need for "landscape ecologists that can penetrate and weave through normal practice showing the benefits of a different approach". All of which needs the "integration of research into spatial ecology with the long-term dynamics of biodiversity changes" and ialeUK to help in developing the policy/practice/ research nexus where the evidence base can be developed "for how to build resilient ecological networks that restore ecosystems at multiple scales in the face of multiple drivers of change".

Reflecting on the role ialeUK has had over the past 25 years also requires some consideration of where it will go in the future. For many respondents, continuing to "support researchers, inform policy makers and practitioners," and "continuing to provide a community of practice" is important. The message here seems to be that what we have been doing well we need to continue doing well, but stressing the need for "multidisciplinary cooperation". For example, some respondents highlighted the need for the aspiration to now develop more collaborative links and work with specific sectors, emphasising "Collaboration with engineering and landscape architects to promote approach" and suggesting, "I think you should work with Landscape Institute [the chartered body for landscape practitioners in the UK] to raise the profile of the discipline and profession". More generally, the call was for "Advocating partnership to deliver better outcomes with limited resources". Across all these areas ialeUK needs to rise to the challenge.

\section{Continuity and diversity}

In the UK, landscape ecology is now part of national policy and adopted widely by all organisations concerned with issues of wildlife, habitat and planning. As such, it is relatively straightforward to find indicators of success ranging from statutory and voluntary national frameworks through to local green infrastructure assessments. Well-known examples include Nature Improvement Areas (Department of Environment Farming and Rural Affairs), Futurescapes (Royal Society for the Protection of Birds), Living Landscapes (Wildlife Trusts), Treescapes (Woodland Trust) Landscape Character Assessment (and EULandscape Directive), Butterfly Conservation's landscape-scale conservation initiatives and Natural England's Accessible Greenspace Criteria. Any of these individual initiatives, but importantly all of them combined, demonstrate the ways in which landscape ecology concepts have been brought into more mainstream planning and nature conservation policy and practice since the chapter came into being. However, ialeUK has not refrained from encouraging a forwardlooking perspective, for example explicitly theming the 2010 conference on 'Future Landscape Ecology' 
to explore where landscape ecology could be going in the UK in the future (Eycott et al. 2010). Many of the themes summarised by Smithers in the 2010 proceedings, for example encouraging understanding of landscape ecology with those who manage our landscapes, recur in most conferences and this appears to therefore remain a challenge. Indeed, this specific point was particularly reinforced by Haines-Young (2017) in the '25 years of landscape ecology' conference held in Manchester where he noted that "while we have made good progress in a number of areas, a persistent concern is that landscape ecological knowledge is not used in decision making as effectively as it might". Thus, despite success in getting the message about landscape ecology out to practitioners and encouraging wider understanding of landscape ecological principles in management, ialeUK needs to continue to aim to help ensure that the discipline plays the significant role in wider sustainability agendas advocated recently (Opdam et al. 2018).

The database of annual conference abstracts we have compiled is extensive and there are myriad ways in which it could be read and analysed. We have focused here primarily on changes through time, but by making the data freely available we hope that interested readers will delve deeper and identify their own insights. The studies analysed here present a series of snapshots concerning the development of landscape ecology in the UK over 25 years since the inception of the UK chapter of IALE, but in general we find:

(1) Clear trends in the affiliation of conference contributors (fewer government representatives), methods (decreasing empirical fieldwork-based studies and increases in qualitative studies), and increases in studies of climate change and ecosystems services with a seeming decrease in studies specifically about connectivity and fragmentation;

(2) Increases in qualitative research, decreases in connectivity/fragmentation and the absence of landscape genetics studies in the UK are seemingly distinct from US landscape ecology and trends in landscape ecology elsewhere around the world (based on published accounts);

(3) ialeUK has had success in increasing the role of understanding gained from landscape ecology research in policy and practice, but needs to continue to aim for improved collaboration with other landscape-related professional bodies and contributions to wider sustainability agendas.

The changing balance of methods and the incorporation of newer concepts indicate a healthy diversity in UK landscape ecology and an ability to adapt in line with wider research developments, policy agendas and in response to new and emerging social and environmental issues (Antrop et al. 2013). This diversification reflects the adoption of ideas from other fields, inspiring innovation in landscape ecology concepts and approaches, the continuation of which should be encouraged in future. Contributors to ialeUK conferences help to maintain the tradition of constructive dialogue championed by Naveh (2007) as one of the critical aspects of IALE and we thank them all for their vital contributions and their ongoing work continuing to develop landscape ecology over the next 25 years.

Acknowledgements We would like to thank everyone who has contributed to the range of ialeUK activities over the past 25 years. Special thanks are given for past committee members and conference organisers who have devoted considerable professional and personal time to the success of ialeUK. We are grateful to Rob Francis, George Perry and two anonymous reviewers for their comments and suggestions during the writing of this manuscript We would finally like to thank all those individuals who generously gave their time to respond to the questionnaire and provide us with the insights into what ialeUK has done and continues to do.

Open Access This article is distributed under the terms of the Creative Commons Attribution 4.0 International License (http:// creativecommons.org/licenses/by/4.0/), which permits unrestricted use, distribution, and reproduction in any medium, provided you give appropriate credit to the original author(s) and the source, provide a link to the Creative Commons license, and indicate if changes were made.

\section{References}

Andersen BJ (2008) Research in the journal Landscape Ecology, 1987-2005. Landsc Ecol 23(2):129-134

Antrop M (2007) Reflecting upon 25 years of landscape ecology. Landsc Ecol 22:1441-1444

Antrop M, Brandt J, Loupa-Ramos I, Padoa-Schioppa E, Porter J, Van Eetvelde V, Pinto-Correia T (2013) How landscape ecology can promote the development of sustainable landscapes in Europe: the role of the European Association for Landscape Ecology (IALE-Europe) in the twenty-first century. Landsc Ecol 28(9):1641-1647 
Chan KMA, Satterfield T, Goldstein J (2012) Rethinking ecosystem services to better address and navigate cultural values. Ecol Econ 74:8-18

Crooks KR, Sanjayan M (2006) Connectivity conservation. Cambridge University Press, New York

Eycott A, Scott D, Smithers RJ (eds) (2010) Future landscape ecology. In: Proceedings of the seventeenth annual conference of ialeUK. ialeUK, Brighton

Farina A (2000) Landscape ecology in action. Kluwer, Dordrecht

Francis RA, Millington JDA, Chadwick MA (eds) (2016) Urban landscape ecology: science, policy and practice. Routledge, London

Fu BJ, Lu YH (2006) The progress and perspectives of landscape ecology in China. Prog Phys Geog 30(2):232-244

Haines-Young R (2017) Landscape Ecology: the long view. 25 years of landscape ecology. In: ialeUK conference, Manchester Metropolitan University, 27-29 June 2017

Handley J, Pauleit S, Slinn P, Barber A, Baker M, Jones C, Lindley S (2003). Accessible natural green space standards in towns and cities: a review and toolkit for their implementation. English Nature Research Report 526

Hernández-Morcillo M, Bieling C, Bürgi M, Lieskovský J, Palang H, Printsmann A, Schulp CJ, Plieninger Verburg PH (2017) Priority questions for the science, policy and practice of cultural landscapes in Europe. Landsc Ecol 32(11):2083-2096

Hong SK, Wu J, Kim JE, Nakagoshi N (eds) (2010) Landscape ecology in Asian cultures. Springer, Berlin

JNCC (2010) History of JNCC. http://archive.jncc.gov.uk/page5305 Accessed: 20/08/2019

LaPoint S, Balkenhol N, Hale J, Sadler J, van der Ree R (2015) Ecological connectivity research in urban areas. Funct Ecol 29(7):868-878

Manel S, Schwartz MK, Luikart G, Taberlet P (2003) Landscape genetics: combining landscape ecology and population genetics. Trends Ecol Evol 18:189-197

McIntyre NE, Iverson LR, Turner MG (2013) A 27-year perspective on landscape ecology from the US-IALE annual meeting. Landsc Ecol 28:1845-1848

Meurk CD, Swaffield SR (2000) A landscape ecological framework for indigenous regeneration in rural New Zealand-Aotearoa. Landsc Urban Plan 50(1-3):129-144

Millington JDA (2019) 25 years of ialeUK conferences: An analysis. https://landscapemodelling.net/book/ialeUK25/

Natural England (2014) National Character Area profiles: data for local decision making. https://www.gov.uk/ government/publications/national-character-area-profilesdata-for-local-decision-making

Naveh Z (2007) Landscape ecology and sustainability. Landsc Ecol 22:1437-1440

ONS (2017) Built-up areas (December 2011) boundaries V2. https://geoportal.statistics.gov.uk/datasets/built-up-areasdecember-2011-boundaries-v2 Accessed 20 Aug 2019

Opdam P, Luque S, Nassauer J, Verburg PH, Wu J (2018) How can landscape ecology contribute to sustainability science? Landsc Ecol 33:1

Plieninger T, Draux H, Fagerholm N, Bieling C, Bürgi M, Kizos T, Kuemmerle T, Primdahl J, Verburg PH (2016) The driving forces of landscape change in Europe: a systematic review of the evidence. Land Use Policy 57:204-214

Reja U, Manfreda K, Hlebec V, Vehovar V (2003) Open-ended vs. close-ended questions in web questionnaires. In: Ferligo J, Mrvar A (eds) Developments in applied statistics. Fakulteta za družbene vede, Ljubjana, pp 159-177

Smithers RJ (2010) How might future landscape ecology avert future tragedy. In: Eycott A, Scott D, Smithers RJ (eds) Future landscape ecology. Proceedings of the seventeenth annual conference of ialeUK. ialeUK, Brighton, pp 190-197

Lawton JH, Brotherton PNM, Brown VK, Elphick C, Fitter AH, Forshaw J, Haddow RW, Hilborne S, Leafe RN, Mace GM, Southgate MP, Sutherland WJ, Tew, TE, Varley J, Wynne GR (2010) Making space for nature: a review of England's wildlife sites and ecological network. Report to Defra. https://webarchive.nationalarchives.gov.uk/ 20130402170324/http:/archive.defra.gov.uk/environment/ biodiversity/documents/201009space-for-nature.pdf

Waller DM, Reo NJ (2018) First stewards: ecological outcomes of forest and wildlife stewardship by indigenous peoples of Wisconsin, USA. Ecol Soc 23(1):45

Wilson O, Hughes O (2011) Urban green space policy and discourse in England under New Labour from 1997 to 2010. Plan Pract Res 26(2):207-228

With K (2019) Essentials of landscape ecology. Oxford University Press, Oxford

Wu J (2017) Thirty years of landscape ecology (1987-2017): retrospects and prospects. Landsc Ecol 32:2225

Publisher's Note Springer Nature remains neutral with regard to jurisdictional claims in published maps and institutional affiliations. 